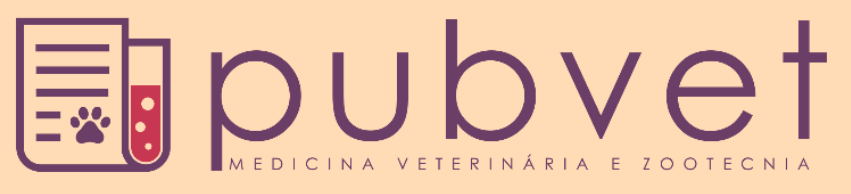

https://doi.org/10.31533/pubvet.v15n07a872.1-5

\title{
A importância da adoção de animais no Brasil
}

\author{
Anderson Scherer ${ }^{1}{ }^{\bullet}$, Carolina D ottaviano Padua de Oliveira Cunha ${ }^{2 *}$, Daniela Barbosa \\ Laureano $^{2}$, Emanuely Victória Rodrigues de Andrade ${ }^{2} \bullet$, Juliana de Freitas Ferreira ${ }^{2}$, Nathalia \\ Braghiroli $^{2}$, Sara Godoy da Silva ${ }^{2}$, Rita Cristina Mendonça ${ }^{2}$
}

${ }^{1}$ Docente do Curso de Medicina Veterinária da Universidade Anhembi Morumbi - UAM - São Paulo, Brasil ${ }^{2}$ Discente do Curso de Medicina Veterinária da Universidade Anhembi Morumbi-UAM - São Paulo, Brasil *Autor para correspondência, E-mail: carolinacunha2009@hotmail.com

\begin{abstract}
Resumo. A adoção pode ser considerada um ato nobre no que diz respeito ao poder que tem em mudar o bem-estar do animal adotado. $\mathrm{O}$ abandono de cães e gatos tem aumentado, fazendo com que tenha muitos animais nas ruas em situações de vulnerabilidade e podendo transmitir zoonoses. As ONGs desempenham um papel extremamente importante, quando se leva em conta o abandono de animais, já que recolhem esses animais em situações de vulnerabilidade lhes proporcionando um novo lar, conscientizando a população e facilitando o processo de adoção. Esta revisão bibliográfica visa a conscientização sobre a importância da adoção animal.
\end{abstract}

Palavras chave: Adoção, conscientização, ONG's

\section{The importance of animal adoption in Brazil}

\begin{abstract}
Adoption can be considered a noble act with regard to the power it has in changing the welfare of the adopted animal. The abandonment of dogs and cats has increased, making it possible to have many animals on the streets in situations of vulnerability and can transmit zoonosis. NGOs play an extremely important role when talking about the abandonment of animals, since they collect these animals in vulnerable situations, providing them with a new home, raising awareness and facilitating the adoption process. This bibliographic review aims to raise awareness about the importance of animal adoption.
\end{abstract}

Keywords: Adoption, awareness, NGOs

\section{Introdução}

O abandono de cães e gatos é uma prática que está aumentando significativamente, resultando em um grande número de animais nas ruas (Pastori \& Matos, 2015). Essa realidade se torna um grande desafio à saúde pública. A preocupação acerca do bem-estar dos animais também está presente, visto que, os animais abandonados podem sofrer agressões, maus-tratos e passam por diversos desafios, como: o medo, o frio, a fome, a sede e possíveis doenças (Leira et al., 2017). Esses desafios, sofridos pelos animais, vão de contramão as cinco liberdades necessárias para o bem-estar animal (Joffily et al., 2013). Dessa maneira, a melhor forma de ajudar é conscientizar a sociedade por completo. A conscientização da população faz com que o índice de abandono diminua e, consequentemente, tenha mais espaço para abrigar os animais que ainda esperam por uma família, visto que, a maioria dos animais doados são abandonados cerca de 14,8 meses depois (Soto et al., 2006). O principal motivo do abandono é o mesmo que dificulta a adoção: falta de informação, responsabilidade e comprometimento dos tutores e da sociedade. Por isso, se faz necessária a participação do governo na conscientização de toda população e incentivo a adoção (Soto et al., 2006). Todo animal tem direito ao cuidado e proteção do homem, sendo assim, o homem é total e exclusivo responsável pelo seu animal (OIE, 2014). 
A participação das ONGs é essencial para que o acolhimento dos animais seja realizado de forma eficaz, posto que, algumas das funções importantes que cabem às ONGs estão relacionadas à conscientização do não abandono e à adoção consciente, pois muitos dos animais resgatados foram abandonados (Pastori \& Matos, 2015). Com isso, se ressalta a real importância das ONGs no processo de adoção, pois além da divulgação, o esclarecimento acerca da adoção consciente e responsável, faz uma grande diferença no destino final destes animais, visto que, ao passar do tempo o convívio aumenta e os cuidados também (Silva et al., 2013).

Pelas revisões bibliográficas em artigos científicos, pesquisas, sites não organizacionais e uma pesquisa de campo com perguntas estruturadas, o objetivo desse trabalho é ressaltar a importância da adoção responsável e conscientizar a população quanto a prática do abandono e adoção dos animais, expondo os cuidados exigidos pelos animais.

\section{Material e métodos}

Na primeira etapa, o trabalho foi realizado com auxílio de uma pesquisa quantitativa e qualitativa, objetivando o levantamento de dados dos artigos científicos, pesquisas e sites de organizações não governamentais.

$\mathrm{Na}$ segunda etapa, foi realizada uma pesquisa de campo com perguntas estruturadas, por meio de um formulário online compartilhado em redes sociais de perguntas e respostas, para adquirir informações de campo - meios de comunicação.

O formulário continha 10 questões, com alternativas de múltiplas escolhas. No final do formulário enviado, os participantes poderiam conhecer os erros e acertos acerca das perguntas; sendo assim, conseguiriam analisar o quanto apto estavam sobre o assunto abordado.

Cada pergunta acertada pelo participante dava a ele um ponto. Foram realizadas dez questões em que os participantes, ao final do processo, poderiam ver seus acertos e erros. Com essa possibilidade, os participantes poderiam realizar uma autocrítica acerca de seus conhecimentos, sobre a importância das ONGs, o processo de adoção e os requerimentos exigidos pelo bem-estar animal.

\section{Resultados e discussão}

O formulário obteve 148 participantes, dos quais, 84,5\% acertaram a primeira questão, 34,5\% acertaram a segunda questão, $100 \%$ acertaram a terceira questão, $70,1 \%$ acertaram a quarta questão, $54,1 \%$ acertaram a quinta questão, $32,6 \%$ acertaram a sexta questão, $96,6 \%$ acertaram a sétima questão, $89,2 \%$ acertaram a oitava questão, $85,1 \%$ acertaram a nona questão, $89,9 \%$ acertaram a décima questão. Assim, entende-se que a média de acertos dos participantes foram oito.

Abaixo seguem as questões supracitadas respectivamente:

1.Sabemos que na maioria das vezes, quando as pessoas pensam em adotar ou comprar um cachorro, optam por cães filhotes. Mas você sabe a vantagem de adotar um animal mais velho (em relação a atividade física do animal)?

2. As ONGs são extremamente importantes quando se leva em conta os animais abandonados. Baseando-se nisso, qual é a quantidade de animais abandonados que estão sob cuidados de ONGs no Brasil, atualmente?

3. Você sabe quais vacinas são necessárias para o bem-estar do seu cão?

4. Você acha que para adotar um gato é obrigatório haver redes/telas de proteção na residência?

5. Você sabe quanto tempo é necessário para o pet se adaptar em um novo lar antes que a pessoa possa rescindir o contrato de adoção?

6.Qual a diferença entre a ração seca e úmida? A ração úmida serve somente como petisco?

7. O que fazer quando for deixar o animal muito tempo sozinho?

8. Você sabe quais documentos são necessários para realizar a adoção de um pet, dependendo da ONG, na hora de preencher a ficha?

9. Pode-se fornecer ração de filhote para um animal adulto? A ração para filhotes pode causar algum problema de saúde em animais adultos?

10. Você sabe quais alimentos são indicados para o seu pet? 
A média de acertos obtida pelo formulário, indica que os participantes possuem informações razoáveis em relação ao processo de adoção, importância das ONGs e os requerimentos exigidos para o bem-estar animal.

No Brasil, o abandono de animais é crescente. Essa realidade faz com que se tenha um elevado número de cães e gatos nas ruas das grandes e pequenas cidades brasileiras, tornando-se um longo desafio à saúde pública, já que estes animais podem causar agressões, poluição ambiental, transmissão de zoonoses e acidentes de trânsito fatais. $\mathrm{O}$ bem-estar animal também é uma preocupação diante dessa realidade, pois existe a prática de maus-tratos, o que torna o trabalho das ONGs ainda mais difícil (Joffily et al., 2013). Os animais, hoje em situação de rua, muitas vezes tiveram um lar, mas acabaram sendo abandonados por seus próprios donos por questões culturais, socioeconômicas e até mesmo religiosas (Pastori \& Matos, 2015). Desse modo, diversas estratégias vêm sendo adotadas, tais como: controle reprodutivo, educação para a guarda responsável e incentivo à adoção por meio de campanhas (Garcia, 2014).

Os principais motivos de abandono de cachorros e gatos foram: ninhadas inesperadas (14\%), mudança de casa $(13,7 \%)$, fatores econômicos $(13,2 \%)$, perda de interesse pelo animal $(11,2 \%)$ e comportamento problemático do animal de estimação (11\%) justificados na tabela 1. Entre os motivos menos frequentes temos: fim da temporada de caça $(10,2 \%)$, alergia de algum membro da família $(7,7 \%)$, nascimento de um filho $(6,4 \%)$, internamento ou morte do proprietário $(3,5 \%)$, férias $(2,6 \%)$ ou o medo de pegar toxoplasmose durante a gravidez $(2,4 \%)$ (Ouriques, 2018).

$\underline{\text { Tabela 1. Justificativas de abandonos de cães e gatos no Brasil }}$

\begin{tabular}{|c|c|c|c|}
\hline Cães & $\%$ & Gatos & $\%$ \\
\hline Suja a casa & 18,5 & Suja a casa & 37,7 \\
\hline Destrutivo fora de casa & 12,6 & Destrutivo fora de casa & 11,4 \\
\hline Agressivo com as pessoas & 12,1 & Agressivo com as pessoas & 16,9 \\
\hline Tem o vício de fugir de casa & 11,6 & Não se adapta com outros animais & 08,0 \\
\hline Ativo demais & 11,4 & Morde & 09,0 \\
\hline Requer mais atenção & 10,9 & Requer muita atenção & 06,9 \\
\hline Late muito & 10,7 & Destrutivo dentro de casa & 14,6 \\
\hline Morde & 09,7 & Eutanásia por motivos de comportamento & 04,6 \\
\hline Destrutivo dentro de casa & 20,0 & Não amistoso & 06,9 \\
\hline Desobediente & 09,0 & Ativo demais & 04,6 \\
\hline
\end{tabular}

Fonte: (Ouriques, 2018).

O Brasil ocupou a quarta colocação no ranking mundial referente ao abandono de animais, com 132,4 milhões de animais de estimação, divididos entre cães, gatos, aves, peixes e pequenos animais, como répteis e pequenos mamíferos, e esse número cresce a cada ano (ABINPET, 2019). É estimado que o Brasil possui 30 milhões de cães e gatos abandonados, um número muito alto se comparado ao número desses animais adotados. Como consequência disso, tem-se um aumento do número de animais nas ruas, comprometendo o bem-estar animal e a saúde pública (OIE, 2014).

As ONGs possuem uma realidade difícil de ser contornada: entram mais animais em relação aos que saem, ou seja, há mais abandono do que adoções efetivas, destacando ainda a falta de conscientização da população que continua a praticar o abandono de animais (Pastori \& Matos, 2015).

O Brasil possui muitos animais abandonados e este número de abandonos vem crescendo cada dia mais. Mais de 170 mil animais (Figura 1) estão sob os cuidados de 370 ONGs para encontrarem um novo lar (Pastori \& Matos, 2015). O papel das ONGs não é somente recolher os animais por um tempo até achar o novo lar, mas sim, vermifugar, castrar e aplicar vacinas (Pastori \& Matos, 2015). As ONGs apresentam um papel essencial no cenário de animais abandonados, se dedicam a salvar animais vítimas de abandono e maus-tratos, tendo como principal objetivo retirar o animal da rua, cuidar, castrar e encaminhá-los para adoção. Contudo, a falta de espaço torna-se um problema recorrente em diversas ONGs do país, visto que, número de animais abandonados cresce exponencialmente. Por isso, a solução muitas vezes é encontrar um lar temporário para esses animais, recorrendo à ajuda da população (Oliveira, 2016).

Um ponto muito importante na adoção é a condição financeira do tutor, pois cerca de $35 \%$ possuem baixa renda e tem dificuldade em manter os animais da maneira mais adequada, cerca de $15 \%$ alimentam 
seus pets com restos de comida e mais de $50 \%$ não os leva ao veterinário ou procuram por auxílio (Soto et al., 2006).

Os brasileiros estão cada vez mais cientes em relação ao cuidado e ao bem-estar dos animais (Braga et al., 2018). Geralmente, o processo de adoção, realizado pelas ONGs, é bem rígido e rigoroso, mas vem dando certo, pois ajuda a conscientizar ainda mais a população. Mesmo assim há dados de abandonos (Pastori \& Matos, 2015).

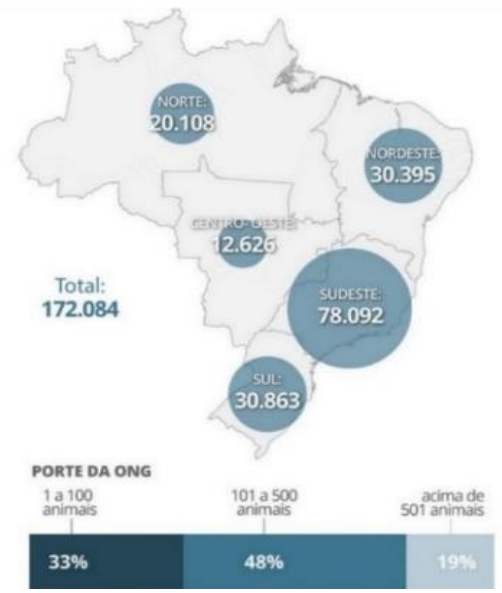

Figura 1. Número de cães e gatos sob cuidado de ONGs e grupos de protetores no brasil. Fonte G1 (2019).

Uma alternativa para conscientizar as pessoas e as incluírem no processo de adoção, é utilizar mecanismos digitais. Embora sejam escassas publicações científicas que se utilizaram de recursos na web para incentivar a adoção de animais, a campanha "Adotar é tudo bom", executada pela marca Pedigree ${ }^{\circledR}$, que empregou a internet como principal meio de divulgação, promoveu a adoção de 43 mil cães segundo dados publicados em seu site oficial (Carpanezi et al., 2016).

A adoção de animais é um ato de amor, pois muitas vezes o animal abandonado já apresenta idade avançada e tudo o que mais precisa é de um lar com carinho e cuidados. O que mais existe são animais de rua precisando de adoção, animais abandonados por seus donos, novas crias de animais que não têm casa e que sem cuidado e castração, gerarão novos animais abandonados, alimentando o círculo de reprodução e abandonos (Moutinho et al., 2019; Oliveira, 2016).

No ano de 1934, criou-se a primeira lei brasileira estabelecendo especificamente "medidas de proteção aos animais". A partir daí todos os animais existentes no país passaram a ser tutelados pelo Estado e os maus-tratos a eles dispensados tornaram-se passíveis de gerar multas e até prisão (Ostos, 2017).

O bem-estar do animal deve estar relacionado com os conceitos de necessidade, felicidade, liberdade, controle, adaptação, capacidade de previsão, sentimentos, sofrimento, dor, ansiedade, medo, estresse e saúde. Tendo em vista a crescente preocupação com esses aspectos e à necessidade de implementação de medidas que visem seu estabelecimento, foi estabelecido "cinco liberdades" como forma de promoção do bem-estar animal: manter os animais livres de fome e sede; manter os animais livres de desconforto físico e de dor; manter os animais livres de injúrias ou doenças; manter os animais livres de medo e estresse; manter os animais livres para que manifestem os padrões comportamentais característicos da espécie (Braga et al., 2018).

\section{Considerações finais}

Normalmente, os animais são abandonados devido à falta de conscientização, aliado com fatores econômicos, sociais e culturais, por parte da sociedade. A alta incidência de animais abandonados afeta o bem-estar dos próprios animais e da população. Diante desse cenário, o papel das ONGs se torna fundamental, já que essas organizações muitas vezes promovem um lar temporário para esses animais e contribuem para uma mobilização social através da conscientização. A conscientização da população faz com que o número de abandonos diminua e ainda faz com que as pessoas sejam estimuladas a realizar o processo de adoção. 
O processo de adoção é muito importante para diminuir a concentração de animais nas ruas das cidades e, como consequência, decrescer a incidência de zoonoses, promovendo uma maior qualidade de vida para a população e para os próprios animais. O acolhimento desses animais deve ser realizado com compreensão, por parte do adotante, levando em conta as exigências do animal, para assim, diminuir a ocorrência de abandonos futuros.

Pelos resultados dos formulários realizados, concluiu-se que os 148 participantes, possuem um conhecimento razoável em relação ao processo de adoção e os requerimentos exigidos pelos animais. As exigências dos animais estão relacionadas às "cinco liberdades". A informação obtida pelo formulário, indica que muitas pessoas realizam o processo de adoção sem conhecer, de maneira adequada, as necessidades requeridas pelos animais, aumentando as chances de abandonos futuros.

\section{Referências}

ABINPET. (2019). Caderno especial Abinpet-Associação Brasileira da Indústria de Produtos para Animais de Estimação. Agro Analysis, 35(1), 35-40.

Braga, J. S., Macitelli, F., Lima, V. A., \& Diesel, T. (2018). O modelo dos "Cinco Domínios" do bemestar animal aplicado em sistemas intensivos de produção de bovinos, suínos e aves. Revista Brasileira de Zoociências, 19(2), 204-226.

Carpanezi, C. A., Graças, J. M., \& Pontes, A. (2016). Desenvolvimento de um aplicativo mobile para doação de animais de estimação. Reverte-Revista de Estudos e Reflexões Tecnológicas Da Faculdade de Indaiatuba, 14, 159-166.

G1, (2019) Brasil tem mais de 170 mil animais abandonados sob cuidado de ONGs, São Paulo Disponível em: https://g1.globo.com/sp/sao-paulo/noticia/2019/08/18/brasil-tem-mais-de-170-milanimais-abandonados-sob-cuidado-de-ongs-aponta-instituto.ghtml. Acesso em: 21 de mai. 2020.

Garcia, R. de C. M. (2014). Normas e políticas públicas para controle populacional de cães e gatos. Senciência e Bem-Estar Animal Expandindo Horizontes, 149.

Joffily, D., Souza, L. M., Gonçalves, S. M., Pinto, J. V., Barcellos, M. C. B., \& Alonso, L. S. (2013). Medidas para o controle de animais errantes desenvolvidas pelo grupo Pet Medicina Veterinária da Universidade Federal Rural do Rio de Janeiro. Revista Em Extensão, 12(1), 197-211.

Leira, M. H., Reghim, L. S., Cunha, L. T., Ortiz, L. S., Paiva, C. O., Botelho, H. A., Ciacci, L. S., Braz, M. S., \& Dias, N. P. P. (2017). Bem-estar dos animais nos zoológicos e a bioética ambiental. PUBVET, 11, 545-553. https://doi.org/10.22256/pubvet.v6n11.545-553.

Moutinho, F. F. B., Serra, C. M. B., \& Valente, L. C. M. (2019). Situação pós-adoção dos animais adotados junto a uma Ong de proteção dnimal no estado do Rio de Janeiro. Ciência Animal Brasileira, 20, 1-14. https://doi.org/10.1590/1809-6891v20e-43777.

OIE. (2014). World Organization for Animal Health (W. H. Organization (ed.)). World Health Organization.

Oliveira, A. B. (2016). Índice estatístico de animais domésticos resgatados da rua vs adoção. Revista Dimensão Acadêmica, 1(2), 1-14.

Ostos, N. S. C. de. (2017). A luta em defesa dos animais no Brasil: uma perspectiva histórica. Ciência e Cultura, 69(2), 54-57. https://doi.org/10.21800/2317-66602017000200018.

Ouriques, J. R. (2018). Bem Estar Animal: Um abrigo para cães e gatos vítimas de maus-tratos e abandono em Florianópolis. In Arquitetura-Florianópolis. Universidade do Sul de Santa Catarina.

Pastori, É. O., \& Matos, L. G. (2015). Da paixão à "ajuda animalitária": o paradoxo do "amor incondicional" no cuidado e no abandono de animais de estimação. Caderno Eletrônico de Ciências Sociais, 3(1), 112-132. https://doi.org/10.24305/cadecs.v3i1.12277.

Silva, A. J., Guilloux, A. G. A., Zetun, C. B., Polo, G., Braga, G. B., Panachão, L. I., Santos, O., \& Dias, R. A. (2013). Abandono de cães na América Latina: revisão de literatura. Revista de Educação Continuada Em Medicina Veterinária e Zootecnia Do CRMV-SP, 11(2), 34-41. https://doi.org/10.36440/recmvz.v11i2.16221.

Soto, F. R. M., Ferreira, F., Pinheiro, S. R., Nogari, F., Risseto, M. R., Souza, O., \& Amaku, M. (2006). Dinâmica populacional canina no Município de Ibiúna-SP: estudo retrospectivo. Brazilian Journal of Veterinary Research and Animal Science, 43(2), 178-185.

Histórico do artigo:

Recebido: 21 de janeiro de 2021

Aprovado: 22 de março de 2021
Licenciamento: Este artigo é publicado na modalidade Acesso Aberto sob a licença Creative Commons Atribuição 4.0 (CC-BY 4.0), a qual permite uso irrestrito, distribuição, reprodução em qualquer meio, desde que o autor e a fonte sejam devidamente creditados. 